\title{
Trends in deceased organ donation in Canada
}

\author{
Sam D. Shemie MDCM
}

Cite as: CMAJ 2017 September 25;189:E1204-5. doi: 10.1503/cmaj.170988

See related article at www.cmaj.ca/lookup/doi/10.1503/cmaj.161043

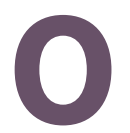

rgan donation and transplantation represent the juxtaposition of the inevitable death of an organ donor with the preventable death of a potential recipient. After decades of stagnant performance, the organ donation and transplantation system in Canada was criticized as being fragmented and in need of redesign. ${ }^{1}$ With concerted effort at provincial and national levels, the system in Canada has recently shown a sustained incremental improvement, ${ }^{2}$ improving the access to lifesaving transplants for Canadians in need of organs.

Canada was a late adopter of donation after circulatory death (DCD) originally called "non-heart-beating" donation, ${ }^{3}$ compared with other countries, owing to early ethical concerns and resistance from the Canadian critical care community. ${ }^{4}$ Through a comprehensive deliberation and multidisciplinary consensus process in 2005, Canada developed the medical, ethical and legal framework for DCD, which was subsequently supported by the Canadian Critical Care Society. ${ }^{5}$ Ontario was an early adopter of the framework. In linked research, Rao and colleagues, comparing Ontario data on the demographics of organ donors, utilization rates, transplantation and time from hospitalization to death, ${ }^{6}$ find a rise in numbers of transplants in the province over a 12 -year period that is almost entirely attributable to DCD. This important finding is instructive for the country. Substantial variation in organ donation rates between provinces still exists ${ }^{2}$ and can be explained largely by variable degree of $D C D$ implementation.

Following the criticisms of a decade ago, the performance of the organ donation and transplantation system in Canada has improved considerably. Each year, increasing numbers of Canadians and their families compassionately and benevolently agree to organ donation at the time of the tragic loss of a loved one. The period from 2006 to 2015 saw a $42 \%$ increase in total number of deceased donors and a $31 \%$ increase in deceased donor transplants. ${ }^{2}$ In our complex health care system, this has been the result of collaborative efforts between hospitals, intensive care units, emergency departments, provincial organ donation organizations, transplant programs, professional societies representing critical care and transplantation, and Canadian Blood Services, the agency tasked by the federal and provincial governments to coordinate the donation and transplant system (https://blood.ca/sites/default/files/otdt-indx-final-c2a.pdf).

The linked research emphasizes the vital contribution of DCD to Canadian transplant rates and the shifting demographics of

\section{KEY POINTS}

- The recent observed improvements in deceased organ donation and transplant rates in Ontario and Canada are almost entirely based on the implementation of donation after circulatory death (DCD).

- There have been demographic shifts in the cause of death before organ donation, with a decreasing incidence of traumatic brain injury. Anoxic brain injury after resuscitated cardiac arrest has become a leading cause of death that results in deceased organ donation.

- Key elements of system improvement in organ donation are implementing DCD, hiring of donation-focused personnel (physicians and nurse coordinators) and the legal requirement to identify and refer all potential donors.

- Increases in resuscitated cardiac arrest will also increase organ donation.

deceased donors. ${ }^{6}$ In contrast, a large observational study in southern Alberta found a declining incidence of brain death, especially in those with head trauma, and a shift toward anoxic brain injury after resuscitated cardiac arrest was the main cause of neurologic death. ${ }^{7}$ These findings have implications for the availability of organs for transplantation in patients with endstage organ failure. Any increases in cardiopulmonary resuscitation and resuscitated cardiac arrest, although intended to save the patient's life, will also increase anoxic brain injury and organ donation. Recent reports of a rise in organ donation associated with the tragic opioid epidemic in North America provide evidence of this. $^{8}$

Organs from donors with anoxic brain injury after resuscitated cardiac arrest are more likely to have had preceding anoxicischemic injury, which means that fewer organs are transplanted. Specific to $D C D$, an increase in warm ischemic injury to organs during the dying process is associated with delayed graft function after kidney transplantation, ischemic cholangiography after liver transplantation and inability to transplant the arrested DCD heart. ${ }^{9}$ Organ utilization, or the number of transplants per donor, is lower with DCD than with donation after neurologic death (2.37 v. 3.38). ${ }^{6}$ An increase in the rate of DCD will increase the number of transplants, but with less efficiency than donation 
after neurologic death and, at times, with lower-quality transplant outcomes. Reassuringly, the widening availability of exvivo organ reperfusion techniques and adoption of techniques used in successful DCD heart transplantation internationally ${ }^{10}$ may mitigate this issue in Canada.

Although there are many elements fundamental to improving the organ donation system, the factors that have most impact are hiring donation-focused personnel (physicians and nurse coordinators), legally requiring all potential donors to be identified and referred, and implementing DCD. ${ }^{2}$ The different Alberta ${ }^{7}$ and Ontario experiences ${ }^{6}$ are of interest in evaluating the impact of DCD on neurologic determination of death. Before southern Alberta implemented DCD and because at the time it did not have a donation physician program, the region had witnessed a decrease in the incidence in brain death. ${ }^{11}$ Ontario has seen an increase in both DCD and donation following brain death and temporally in association with implementing donation physicians. ${ }^{12}$ This suggests that implementation of a DCD program in association with intensive care unit physicians who are focused on donation therefore drives the improvement of all forms of deceased organ donation.

Can DCD programs reduce brain death and inadvertently lead to a decrease in the number of transplantable organs, particularly hearts? If they did, this would imply that donors after circulatory death die earlier than donors with neurologic death; i.e., before the devastating brain injury can deteriorate to brain death. The linked study from Ontario seems to show the opposite. Mean length of hospital stay before declaration of neurologic death in donors was 2.7 days versus 6.0 days before withdrawal of life support and subsequent asystole in donors following circulatory death. The authors conclude that there is no evidence that the use of DCD was pre-empting potential donations following neurologic death. This conclusion would be strengthened if the comparative time to death had been adjusted for the specific cause of brain injury (e.g., anoxic brain injury).

Canada's gradual improvement in donation and transplant rates, although gratifying, will require ongoing and increasing effort. The 2015 rate of 18.2 donors per million population ${ }^{2}$ remains well below estimates of donor potential, which range from $40-50$ by provincial death audit reports (www.cmq.org/publications/index.aspx?s=don+d\%27organe $\& p=1$ ) to 89 , estimated by the Canadian Institute for Health Information (www.cihi.ca/ web/resource/en/organdonorpotential_2014_en.pdf). Recent evolving trends in the demographics of deceased organ donation are noteworthy for Canada and informative for future investment in the system by health care organizations, funders and policy-makers.

\section{References}

1. Gill JS, Klarenbach S, Cole E, et al. Deceased organ donation in Canada: an opportunity to heal a fractured system. Am J Transplant 2008;8:1580-7.

2. Organ donation and transplantation in Canada: system progress report 20062015. Ottawa: Canadian Blood Services; 2016. Available: https://blood.ca/sites/ default/files/ODT_Report.pdf (accessed 2017 Aug. 21).

3. Knoll GA, Mahoney JE. Non-heart-beating organ donation in Canada: Time to proceed? CMAJ 2003;169:302-3.

4. Rocker GM. Organ and tissue donation in the intensive care unit. CMAJ 2002;167:1248-9.

5. Shemie SD, Baker AJ, Knoll G, et al. National recommendations for donation after cardiocirculatory death in Canada: donation after cardiocirculatory death in Canada. CMAJ 2006;175:S1.

6. Rao V, Dhanani S, Maclean J, et al. Effect of organ donation after circulatory determination of death on number of organ transplants from donors with neurologic determination of death. CMAJ 2017;189:E1206-11.

7. Kramer AH, Zygun DA, Doig CJ, et al. Incidence of neurologic death among patients with brain injury: a cohort study in a Canadian health region. CMAJ 2013; 185:E838-45.

8. Goldberg DS, Blumberg E, McCauley M, et al. Improving organ utilization to help overcome the tragedies of the opioid epidemic. Am J Transplant 2016;16:2836-41.

9. Hernadez-Alejandro R, Wall W, Jevnikar A, et al. Organ donation after cardiac death: donor and recipient outcomes after the first three years of the Ontario experience. Can J Anaesth 2011;58:599-605.

10. Macdonald PS. Heart transplantation from DCD donors: from the bedside to the bench. Transplantation 2017;101:1753-4.

11. Kramer AH, Baht R, Doig CJ. Time trends in organ donation after neurologic determination of death: a cohort study. CMAJ Open 2017;5:E19-27.

12. Shemie SD, MacDonald S; Canadian Blood Services - Canadian Critical Care Society Expert Consultation Group. Improving the process of deceased organ and tissue donation: a role for donation physicians as specialists. CMAJ 2014;186:95-6.
Competing interests: Sam Shemie reports that in addition to being a member of the Division of Critical Care Medicine, Montreal Children's Hospital McGill University Health Centre \& Research Institute, and Professor of Pediatrics, McGill University, he is the Medical Advisor for Deceased Organ Donation at Canadian Blood Services.
Affiliations: Division of Critical Care Medicine, Montreal Children's Hospital, McGill University Health Centre \& Research Institute; McGill University; Deceased Organ Donation, Canadian Blood Services, Montréal, Que.

This article was solicited and has not been peer reviewed.

Correspondence to: Sam Shemie, sam.shemie@mcgill.ca 